\title{
Torsional Dynamics and 2D Speckle Tracking in Heart Failure with Reduced Ejection Fraction on Patients Taking Sacubitril/Valsartan and Naive
}

\author{
Wassam EL Din EL Shafey, Walaa Faried, Mena Emad Shafek, Ehab Kamal EL Melegy \\ Cardiology Department, Faculty of Medicine, Menoufia University, Al Minufya, Egypt \\ Email: dr_wesamhadad@yahoo.com
}

How to cite this paper: EL Shafey, W.ELDin, Faried, W., Shafek, M.E. and EL Melegy, E.K. (2020) Torsional Dynamics and 2D Speckle Tracking in Heart Failure with Reduced Ejection Fraction on Patients Taking Sacubitril/Valsartan and Naive. World Journal of Cardiovascular Diseases, 10, 294-304.

https://doi.org/10.4236/wjcd.2020.105027

Received: April 7, 2020

Accepted: May 9, 2020

Published: May 12, 2020

Copyright $\odot 2020$ by author(s) and Scientific Research Publishing Inc. This work is licensed under the Creative Commons Attribution International License (CC BY 4.0).

http://creativecommons.org/licenses/by/4.0/ (c) (i) Open Access

\begin{abstract}
This study aims to evaluate the torsional dynamics and 2D speckle tracking in heart failure with reduced ejection fraction on patients taking angiotensin receptor neprilysin inhibitors (ARNI) and none. ARNI has been shown to be superior to enalapril in the long term reducing the mortality and hospitalization of heart failure (HF). However short-term effects on diastolic function remain unclear. We sought to evaluate 6 months' effects of ARNI on left ventricular (LV) diastolic parameters determined by speckle tracking and tissue Doppler imaging. This study was carried out in Menoufia University Hospitals including 60 patients of HFrEF during the period from August 2019 to January 2020. (50\%) of patients were treated with traditional treatment of heart failure and the remaining were treated with ARNI. Data were collected including history and clinical examination. ECG and speckle tracking and tissue Doppler imaging were done to evaluate the diastolic function. Our results showed no significant difference between the two groups at baseline. There was a significant improvement in the LV diastolic function parameters. Untwisting time and untwisting onset showed the highly significant parameters of improvement. This study concluded that ARNI showed short term improvement of diastolic function of the left ventricle that could be detected by STE.
\end{abstract}

\section{Keywords}

HFrEF, ARNI, Speckle Tracking, Untwisting Rate and Untwisting Onset

\section{Introduction}

HF is a clinical syndrome characterized by typical symptoms (e.g. breathlessness, 
ankle swelling and fatigue) that may be accompanied by signs (e.g. elevated jugular venous pressure, pulmonary crackles and peripheral oedema) caused by a structural and/or functional cardiac abnormality, resulting in a reduced cardiac output and/or elevated intracardiac pressures at rest or during stress [1]. HF comprises a wide range of patients, from those with normal LVEF $\geq 50 \%$ (HFpEF) to those with reduced LVEF < 40\% (HFrEF), while patients with an LVEF in the range of $40 \%-49 \%$ represent a "grey area", which is now defined as HFmrEF. Differentiation of patients with HF based on LVEF is important due to different underlying aetiologies, demographics, co-morbidities and response to therapies [2]. Most clinical trials published after 1990 selected patients based on LVEF [usually measured using echocardiography, a radionuclide technique or cardiac magnetic resonance (CMR)], and it is only in patients with HFrEF that therapies have been shown to reduce both morbidity and mortality. The NYHA functional classification has been used to describe the severity of symptoms and exercise intolerance. However, symptom severity correlates poorly with many measures of LV function; although there is a clear relationship between the severity of symptoms and survival; patients with mild symptoms may still have an increased risk of hospitalization and death [3] [4]. Heart failure is a common, costly, and potentially fatal condition. In 2015, it affected about 40 million people globally [5]. Overall around 2\% of adults have heart failure [6] and in those over the age of 65 , this increases to $6 \%-10 \%$ [7] [8]. Rates are predicted to increase [6]. The risk of death is about $35 \%$ the first year after diagnosis, while by the second year the risk of death is less than $10 \%$ for those who remain alive [9]. The goals of treatment for people with chronic heart failure are the prolongation of life, the prevention of acute decompensation and the reduction of symptoms and allowing for greater activity [10]. Sacubitril/valsartan was developed by Novartis. It is recommended for use as a replacement for an ACE inhibitor or an angiotensin receptor blocker in people with heart failure with reduced ejection fraction [11]. It was approved under the FDA's priority review process on July 7, 2015 [12]. Speckle-tracking echocardiography is a relatively new noninvasive ultrasound imaging technique that allows for an objective and quantitative evaluation of global and regional myocardial function [11] [13].

\section{Methods}

\subsection{Subjects}

This study was carried out in Menoufia University Hospital. The study included 60 patients of heart failure with reduced ejection fraction in the outpatient clinic of the cardiology department and randomly assigned into two matched groups each contain 30 patients. $50 \%$ of patients were treated with traditional treatment of heart failure and the other $50 \%$ patients were treated with ARNI. Full history was taken and full clinical examination was done. Baseline vital signs, ECG, NYHA classification, TTE and STE were done and after 6 months to make a comparison between the two groups. 


\subsection{Ethical Clearance}

The study protocol was approved by the local ethics committee of the Menoufia University and written consent was obtained from the patients.

\subsection{Study Period}

The patients in this study were followed up during the period from August 2019 to the end of January 2020.

\subsection{Standard Echo-Doppler Study}

Standard echo-Doppler was performed using a GE vivid e9 ultrasound system (GE Vingmed Ultrasound AS, Horten, Norway). Cine-loops were recorded on DVDs for offline analysis (EchoPAC PC 6.0.0, GEMedical Systems). All the measurements were analysed taking the average of three cardiac cycles.LV diameter and wall thickness were measured according to the criteria of the American Society of Echocardiography [14].

Left atrium (LA) volume was determined by the biplane-area-length method [15]. Two-dimensional measurements of LV wall thickness were assessed in four segments (anterior and posterior interventricular septum, inferior, and antero-lateral walls) at the mitral valve, papillary muscles and apical levels by parasternal short-axis views. In addition, LV EF was calculated by the Simpson biplane method [16]. As measures of global LV diastolic function peak velocities at the early (peak E) and late (peak A) diastole, their ratio, deceleration time of the $\mathrm{E}$ wave and isovolumic relaxation time (IVRT) were assessed by pulsed-Doppler with the sample volume placed at the mitral valve leaflet tips and at the aortic outflow [17]. Finally, by pulsed tissue Doppler, peak early diastolic velocity on the septal part of the mitral annulus was measured (E') and E/E' ratio was calculated.

\subsection{Speckle Tracking Imaging Study}

For the STI study, the second-harmonic B-mode images of apical (4-chamber, 2-chamber, and 3-chamber) and short-axis (at the mitral valve and apical level) views were obtained. The LV endocardial border was manually traced at the end-systolic frame and a speckle tracking region of interest was automatically selected. The width of the region of interest was adjusted as necessary to accommodate the total thickness of the LV wall. The computer automatically tracked stable objects in each frame using the sum of absolute differences algorithm. After these steps, the work station computed and generated strain curves. For assessment of LV rotational mechanics through scanning and recording from left para-sternal short-axis view of both basal and apical short-axis planes to quantify basal and apical LV rotations using the same probe, with a frequency range $1.7-2.0 \mathrm{MHz}$ at a high frame rate (range: $80-115$ frame/s).

The basal level was marked as the plane showing the tips of mitral valve leaflets at its center with full-thickness myocardium surrounding the mitral valve. Then the transducer was positioned one or two intercostal spaces more caudal and slightly lateral from the basal site to be perpendicular to the apical imaging 
plane [18]. The apical level was defined just proximal to the level of LV apical luminal obliteration at the end-systole. The cross-section must be as circular as possible. We have to pay careful attention to ensure that full thickness of myocardium is imaged throughout the cardiac cycle.

To analyze twist and untwisting parameters, from the basal and apical short axis, data set with a well defined endo-cardial border and the regions of interest were adjusted to include all myocardial thickness without including the pericardium. The endocardial borders of both basal and short axis planes were manually traced and subsequently tracked by the software. If poor tracking quality was observed, the region of interest was readjusted until acceptable tracking was obtained. After processing, curves of basal and apical LV rotation, twist, twist rate, and untwisting rate were automatically generated by the software (Excel; Microsoft Corporation, Redmond, Washington, USA). Twist was calculated as apical rotation relative to the basal rotation, with counterclockwise rotation as viewed from LV apex expressed as positive value and clockwise rotation as a negative value. Peak LV twist, peak LV twist rate (as first positive peak after R wave on ECG), and peak LV untwisting rate (as the first negative peak after aortic valve closure) were recorded. Cardiac cycle length was measured as R-R interval. Time to peak twist rate was measured as time from $\mathrm{R}$ wave to peak twist rate, and time to peak untwisting rate was measured as time from $\mathrm{R}$ wave to peak untwisting rate.

\subsection{Statistical Analysis}

Data were analyzed using Statistical Program for Social Science (SPSS) version 25.0 for windows (SPSS Inc., Chicago, IL, USA). Quantitative data of normal distribution were expressed as mean \pm standard deviation (SD). Qualitative data were expressed as frequency and percentage. Independent-samples t-test of significance was used when comparing two means of normally distributed data. Chi-square $\left(\mathrm{X}^{2}\right)$ test also called Pearson's chi-square test or the chi-square test of association, is used to discover if there is a relationship between two categorical variables. Fisher Exact test is a test of significance that is used in the place of chi square test in 2 by 2 tables, especially in cases of small samples. The "Linear-by-Linear" test is for ordinal (ordered) categories and assumes equal and ordered intervals. The Linear-by-Linear Association test is a test for trends in a larger than $2 \times 2$ table. The Paired Samples t-test compares two means that are from the same individual, object, or related units. The two means typically represent two different times (e.g., pre-test and post-test with an intervention between the two-time points). The purpose of the test is to determine whether there is statistical evidence that the mean difference between paired observations on a particular outcome is significantly different from zero. Probability ( $\mathrm{p}$-value): $\mathrm{p}$-value $\leq 0.05$ was considered significant, $\mathrm{p}$-value $\leq 0.001$ was considered as highly significant and $\mathrm{p}$-value $>0.05$ was considered insignificant.

\section{Results}

A total of 60 symptomatic patients of which males represent (41) $68.3 \%$. The 
mean age of total study population was $66.8 \pm 11$ years. Hypertension was the most prevalent risk factor (52) $86.7 \%$ (Table 1). At baseline no significant difference between the two groups regarding age, gender, other risk factors, NYHA classification or any echocardiography parameter that we compared (Table 2). After 6 months of treatment comparing the two groups statically, there was an improvement in the results of ARNI group as follows significant improvement in NYHA classification $(\mathrm{P}=0.006)$ (Table 3$)$. Improving Diastolic dysfunction grading $(\mathrm{P}=0.008)$. $\mathrm{E} / \mathrm{A}$ ratio $(\mathrm{P}=0.002)$. $\mathrm{E} / \mathrm{e}^{\prime}(\mathrm{P}=<0.001)$, and a significant reduction in TR velocity $(\mathrm{m} / \mathrm{s})(\mathrm{P}=0.003)$ (Table 4$)$. Untwisting rate $(\% / \mathrm{s}) \mathrm{pa}-$ rameter showed statistically high significant improvement in the ARNI group vs the traditional one $(\mathrm{P}<0.001)(-65.4 \pm 5.2$ vs $-60.4 \pm 4.5)$. Finally untwisting onset (ms) showed significant improvement in the ARNI group vs the traditional one $(\mathrm{P}=0.028)(96.8 \pm 16.2$ vs $106.1 \pm 15.7)($ Table 5$)$.

Table 1. Comparison between the studied groups regarding the baseline characteristics.

\begin{tabular}{cccc}
\hline Baseline characteristics & ARNI & Traditional & $\begin{array}{c}\text { P-value } \\
\text { (Sig.) }\end{array}$ \\
\hline Count & 30 & 30 & 0.184 (NS) \\
Age (years) & $68.7 \pm 12.2$ & $64.9 \pm 9.5$ & \\
Male gender & Demographic data & $22(73.3 \%)$ & 0.405 (NS) \\
DM & $19(63.3 \%)$ & $24(80 \%)$ & 0.243 (NS) \\
HTN & $20(66.7 \%)$ & $28(93.3 \%)$ & 0.254 (NS) \\
Smoking & $24(80 \%)$ & $21(70 \%)$ & 0.584 (NS) \\
Anemia & $19(63.3 \%)$ & $20(66.7 \%)$ & 0.243 (NS) \\
\hline
\end{tabular}

$\mathrm{p}<0.05$ is significant; Sig.: significance.

Table 2. Comparison between the studied groups regarding the baseline echocardiographic diastolic parameters.

\begin{tabular}{cccc}
\hline $\begin{array}{c}\text { Baseline echocardiographic } \\
\text { diastolic parameters }\end{array}$ & ARNI & Traditional & $\begin{array}{c}\text { P-value } \\
\text { (Sig.) }\end{array}$ \\
\hline Count & 30 & 30 & \\
\hline $\begin{array}{c}\text { Diastolic dysfunction grade } \\
\text { Grade 1 }\end{array}$ & $2(6.7 \%)$ & $0(0 \%)$ & 0.409 (NS) \\
Grade 2 & $22(73.3 \%)$ & $23(76.7 \%)$ & \\
Grade 3 & $6(20 \%)$ & $7(23.3 \%)$ & 0.107 (NS) \\
E/A & $1.12 \pm 0.30$ & $1.25 \pm 0.30$ & 0.069 (NS) \\
E/e' & $10.5 \pm 1.8$ & $11.3 \pm 1.8$ & $0.079(\mathrm{NS})$ \\
TR velocity (m/s) & $2.7 \pm 0.3$ & $2.9 \pm 0.3$ & \\
Speckle diastolic parameters & & & $0.190(\mathrm{NS})$ \\
Untwisting rate $\left({ }^{\circ} / \mathrm{s}\right)$ & $-61.6 \pm 4.7$ & $-60.0 \pm 4.5$ & 0.297 (NS) \\
Untwisting onset (ms) & $102.9 \pm 16.0$ & $107.4 \pm 16.8$ &
\end{tabular}


Table 3. Comparison between the studied groups regarding the NYHA class after 6 months.

\begin{tabular}{cccc}
\hline NYHA class after 6 months & ARNI & Traditional & $\begin{array}{c}\text { P-value } \\
\text { (Sig.) }\end{array}$ \\
\hline Count & 30 & 30 & \\
NYHA class & $4(13.3 \%)$ & $1(3.3 \%)$ & $0.006(\mathrm{~S})$ \\
Class 1 & $18(60 \%)$ & $10(33.3 \%)$ & \\
Class 2 & $7(23.4 \%)$ & $16(53.4 \%)$ & \\
Class 4 & $1(3.3 \%)$ & $3(10 \%)$ & \\
\hline
\end{tabular}

$\mathrm{p}<0.05$ is significant; Sig.: significance.

Table 4. Comparison between the studied groups regarding the echocardiographic diastolic parameters after 6 months.

\begin{tabular}{|c|c|c|c|}
\hline $\begin{array}{l}\text { Echocardiographic diastolic } \\
\text { parameters after } 6 \text { months }\end{array}$ & ARNI & Traditional & P-value \\
\hline Count & 30 & 30 & \\
\hline \multicolumn{4}{|l|}{ Diastolic dysfunction grade } \\
\hline Grade 1 & $9(30 \%)$ & $1(3.3 \%)$ & \\
\hline Grade 2 & $18(60 \%)$ & $22(73.4 \%)$ & $0.008(\mathrm{~S})$ \\
\hline Grade 3 & $3(10 \%)$ & $7(23.3 \%)$ & \\
\hline \multicolumn{4}{|c|}{ Other Doppler diastolic parameters } \\
\hline $\mathrm{E} / \mathrm{A}$ & $0.93 \pm 0.30$ & $1.16 \pm 0.26$ & $0.002(\mathrm{~S})$ \\
\hline $\mathrm{E} / \mathrm{e}^{\prime}$ & $9.1 \pm 1.9$ & $10.8 \pm 1.6$ & $<0.001(\mathrm{HS})$ \\
\hline TR velocity $(\mathrm{m} / \mathrm{s})$ & $2.6 \pm 0.3$ & $2.8 \pm 0.3$ & $0.003(\mathrm{~S})$ \\
\hline \multicolumn{4}{|l|}{ Speckle diastolic parameters } \\
\hline Untwisting rate $(\% / s)$ & $-65.4 \pm 5.2$ & $-60.4 \pm 4.5$ & $<0.001(\mathrm{HS})$ \\
\hline Untwisting onset (ms) & $96.8 \pm 16.2$ & $106.1 \pm 15.7$ & $0.028(\mathrm{~S})$ \\
\hline
\end{tabular}

$\mathrm{p}<0.05$ is significant; Sig.: significance.

Table 5. Comparison between the studied groups regarding the speckle diastolic parameters at baseline and after 6 months.

\begin{tabular}{lccc}
\hline Speckle diastolic parameters & At baseline & After 6 months & P-value (Sig.) \\
\hline ARNI group $(\mathrm{n}=30)$ & & & \\
Untwisting rate $(\%)$ & $-61.6 \pm 4.7$ & $-65.4 \pm 5.2$ & $<0.001(\mathrm{HS})$ \\
Untwisting onset $(\mathrm{ms})$ & $102.9 \pm 16.0$ & $96.8 \pm 16.2$ & $0.003(\mathrm{~S})$ \\
Traditional treatment group $(\mathrm{n}=30)$ & & $-60.4 \pm 4.5$ & $0.031(\mathrm{~S})$ \\
Untwisting rate $(\%)$ & $-60.0 \pm 4.5$ & $106.1 \pm 15.7$ & $0.068(\mathrm{NS})$ \\
Untwisting onset $(\mathrm{ms})$ & $107.4 \pm 16.8$ & & \\
\hline
\end{tabular}

$\mathrm{p}<0.05$ is significant; Sig.: significance. 


\section{Discussion}

Our prospective observational study of patients with HFrEF showed that, the group of patients on ARNI showed a remarkable improvement in the reverse remodeling parameters by reducing left ventricular filling pressure, MR, TR and diastolic function that measured by $2 \mathrm{D}$ conventional echocardiography (E/A ratio, E/e' ratio and TR velocity) and also by $2 \mathrm{D}$ STE (untwisting onset and untwisting rate). These hemodynamic effects produced by ARNI help in reduction of NYHA classes and improving patient's symptomatology. In addition to their vasodilatory, natriuretic, diuretic effects, natriuretic peptides inhibit the RAAS, sympathetic nervous system, and consequent release of antidiuretic hormone, improve myocardial relaxation and vagal tone, and have antifibrotic and antihypertrophic properties [19] [20]. Mechanistically, sacubitril is implicated in attenuating cardiomyocyte cell death, hypertrophy, and impaired myocyte contractility [21]. Based on these preclinical and mechanistic evaluations of sacubitril, the incremental beneficial effect systolic and diastolic function might seem more intuitive than expected. However prospective data regarding sacubitril-valsartan and cardiac remodeling are limited: Martens and colleagues [22] reported a 5\% mean improvement in LVEF after a follow-up period of 4 months. The recent PROVE-HF study [23] adds information regarding associations between ARNI therapy, change in NT-proBNP, and cardiac remodeling. Reduction in NT-proBNP following treatment with sacubitril-valsartan was associated with an increase in LVEF and reductions in indexed LV and LA volumes as well as $\mathrm{E} / \mathrm{e}^{\prime}$ ratio. In line with this finding we found statistical non-significant difference between ARNI and traditional treatments as regard LVEF by 2D conventional echo and global longitudinal strain by 2D-STE. On the other hand, we found a statistical significant improvement between ARNI and traditional treatments in $\mathrm{E} / \mathrm{A}$ ratio, E/e' ratio and TR velocity that may implicate the LV reverse remodeling effect mediated by ARNI. At the best of our knowledge this is the first study to report an improvement in untwisting rate and untwisting onset of the left ventricle in patients on Sacubitril/Valsartan therapy which evaluated by 2D STE. Both are important prognostic measures and reflecting the severity and chronicity of elevated cardiac filling pressures, LV negative remodeling and fluid congestion this improvement determine reduction in TR velocity. The observed benefit of ARNI in reducing not only E/A ratio, E/e', MR and TR classes, TR velocity and improvement of the diastolic function grading but also a significant improvement in untwisting rate and untwisting onset of the left ventricle which may explain the remarkable significant improvement in NYHA class observed in our patients. The improvement of E/A ratio in our data was previously observed with Giuseppe Romano and colleagues in 2019 [24]. Coherently with echocardiographic measurements, neprilysin inhibition mediated by sacubitril acutely amplified the hemodynamic effects of natriuretic peptides determining natriuresis and vasodilation [25] [26]. Moreover ARNI outperformed angiotensin-converting enzyme inhibitors/angiotensin receptor blockers in terms of cardiac reverse re- 
modeling with striking changes in left ventricular EF, diameter, and volume [27]. Our study approved that by showing a reduction of percentage of patients in NYHA class III and an increasing number of patients in NYHA class I and II at follow up. Since LV torsion is the wringing motion, or twist of the heart imparted by contraction of its oblique spiral fibers [26] [27]. Counterclockwise torsion develops during systolic ejection, whereas the clockwise recoil of torsion, or untwisting, constitutes the deformation that largely occurs during the period of isovolumic relaxation [28] [29]. This recoil is associated with the release of restoring forces that accumulate during systole and is thought to contribute towards diastolic suction, which is a major determinant of early LV filling [27] [28], so ARNI improves LV filling through improvement of untwisting rate and untwisting onset and as a following result improves all parameters of diastolic function as an early detection parameter.

\section{Conclusion}

The study concluded that HFrEF patients treated with Sacubitril/Valsartan for 6 months duration showed significant improvement of the LV diastolic functional parameters assessed by measuring untwist onset and untwist rate by $2 \mathrm{D}$ speckle tracking echocardiography in coincidence with remarkable improvement of NYHA functional class and symptomatology.

\section{Limitation}

One of the limitations was the small sample size of the study.

\section{Acknowledgements}

This study was supported by the cardiology department at Menoufia University.

\section{Conflicts of Interest}

The authors declare no conflicts of interest regarding the publication of the study of this paper.

\section{References}

[1] Ponikowski, P., Voors, A.A., Anker, S.D., Bueno, H., Cleland, J.G.F., Coats, A.J.S., et al. (2016) 2016 ESC Guidelines for the Diagnosis and Treatment of Acute and Chronic Heart Failure. European Heart Journal, 37, 2129-2200. https://doi.org/10.1093/eurheartj/ehw128

[2] Butler, J., Fonarow, G.C., Zile, M.R., Lam, C.S., Roessig, L., Schelbert, E.B., Shah, S.J., Ahmed, A., Bonow, R.O., Cleland, J.G.F., Cody, R.J., Chioncel, O., Collins, S.P., Dunnmon, P., Filippatos, G., Lefkowitz, M.P., Marti, C.N., McMurray, J.J., Misselwitz, F., Nodari, S., O’Connor, C., Pfeffer, M.A., Pieske, B., Pitt, B., Rosano, G., Sabbah, H.N., Senni, M., Solomon, S.D., Stockbridge, N., Teerlink, J.R., Georgiopoulou, V.V. and Gheorghiade, M. (2014) Developing Therapies for Heart Failure with Preserved Ejection Fraction: Current State and Future Directions. JACC Heart Fail, 2, 97-112. https://doi.org/10.1016/j.jchf.2013.10.006 
[3] McMurray, J.J.V. (2010) Clinical Practice. Systolic Heart Failure. New England Journal of Medicine, 3623, 228-238.

[4] Dunlay, S.M., Redfield, M.M., Weston, S.A., Therneau, T.M., Hall Long, K., Shah, N.D. and Roger, V.L. (2009) Hospitalizations after Heart Failure Diagnosis A Community Perspective. Journal of the American College of Cardiology, 54, 1695-1702. https://doi.org/10.1016/j.jacc.2009.08.019

[5] McDonagh, T.A., Dargie, H.J., Szwejkowski, B.R., Rekhraj, S., Struthers, A., Adamopoulos, S., Georgiadou, P. and Voudris, V. (2011) Pathophysiology of Heart Failure. In: Oxford Textbook of Heart Failure, Oxford University Press, Oxford, 131. https://doi.org/10.1093/med/9780199577729.003.0013

[6] Solomon, S.D., Dobson, J., Pocock, S., Skali, H., McMurray, J.J., Granger, C.B., Yusuf, S., Swedberg, K., Young, J.B., Michelson, E.L. and Pfeffer, M.A. (2007) Influence of Nonfatal Hospitalization for Heart Failure on Subsequent Mortality in Patients with Chronic Heart Failure. Circulation, 116, 1482-1487.

https://doi.org/10.1161/CIRCULATIONAHA.107.696906

[7] Antzelevitch, C., Brugada, P., Borggrefe, M., Brugada, J., Brugada, R., Corrado, D., Gussak, I., LeMarec, H., Nademanee, K., Perez Riera, A.R. and Shimizu, W. (2005) Brugada Syndrome: Report of the Second Consensus Conference: Endorsed by the Heart Rhythm Society and the European Heart Rhythm Association. Circulation, 111, 659-670. https://doi.org/10.1161/01.CIR.0000152479.54298.51

[8] Entresto, F.L. (2015) (Sacubitril/Valsartan): First-in-Class Angiotensin Receptor Neprilysin Inhibitor FDA Approved for Patients with Heart Failure. American Health \& Drug Benefits, 8, 330.

[9] Vos, T., Allen, C., Arora, M., Barber, R.M., Bhutta, Z.A., Brown, A., Carter, A., Casey, D.C., Charlson, F.J., Chen, A.Z. and Coggeshall, M. (2016) Global, Regional, and National Incidence, Prevalence, and Years Lived with Disability for 310 Diseases and Injuries, 1990-2015: A Systematic Analysis for the Global Burden of Disease Study 2015. The Lancet, 388, 1545-1602.

[10] Metra, M. and Teerlink, J.R. (2017) Heart Failure. The Lancet, 390, 1981-1995. https://doi.org/10.1016/S0140-6736(17)31071-1

[11] Dickstein, K., Cohen-Solal, A., Filippatos, G., McMurray, J.J., Ponikowski, P., Poole-Wilson, P.A., Strömberg, A., van Veldhuisen, D.J., Atar, D. and Hoes, A.W. (2008) ESC Guidelines for the Diagnosis and Treatment of Acute and Chronic Heart Failure 2008: The Task Force for the Diagnosis and Treatment of Acute and Chronic Heart Failure 2008 of the European Society of Cardiology. Developed in Collaboration with the Heart Failure Association of the ESC (HFA) and Endorsed by the European Society of Intensive Care Medicine (ESICM). European Journal of Heart Failure, 10, 933-989.

[12] Boulpaep, E.L., Boron, W.F., Caplan, M.J., Cantley, L., Igarashi, P., Aronson, P.S. and Moczydlowski, E. (2009) Medical Physiology a Cellular and Molecular Approach. Signal Transduction, 48, 27.

[13] Yancy, C.W., Jessup, M., Bozkurt, B., Butler, J., Casey, D.E., Colvin, M.M., Drazner, M.H., Filippatos, G.S., Fonarow, G.C., Givertz, M.M. and Hollenberg, S.M. (2017) ACC/AHA/HFSA Focused Update of the 2013 ACCF/AHA Guideline for the Management of Heart Failure: A Report of the American College of Cardiology/American Heart Association Task Force on Clinical Practice Guidelines and the Heart Failure Society of America. Journal of the American College of Cardiology, 70, 776-803. https://doi.org/10.1161/CIR.0000000000000509

[14] Sahn, D.J., DeMaria, A., Kisslo, J. and Weyman, A. (1978) Recommendations Re- 
garding Quantification in M-Mode Echocardiography: Results of a Survey of Echocardiographic Measurements. Circulation, 58, 1072-1083. https://doi.org/10.1161/01.CIR.58.6.1072

[15] Lester, S.J., Ryan, E.W., Schiller, N.B. and Foster, E. (1999) Best Method in Clinical Practice and Research Studies to Determine Left Atrial Size. American Journal of Cardiology, 84, 829-832. https://doi.org/10.1016/S0002-9149(99)00446-4

[16] Schiller, N., Shah, P.M., Crawford, M., DeMaria, A., Devereux, R., Feigenbaum, H., et al. (1989) Recommendations for Quantification of the Left Ventricle by Two-Dimensional Echocardiography: American Society of Echocardiography Subcommittee on Standards. Journal of the American Society of Echocardiography, 2, 358-368. https://doi.org/10.1016/S0894-7317(89)80014-8

[17] Nagueh, S., Appleton, C.P., Gillebert, T.C., Marino, P.N., Oh, J.K., Smisteh, O.A., et al. (2009) Recommandations of the Evaluation of Diastolic Dysfunctions by Echocardiography. Journal of the American Society of Echocardiography, 22, 108-128. https://doi.org/10.1016/j.echo.2008.11.023

[18] Hollekim-Strand, S.M., Hoydahl, S.F., Follestad, T., Dalen, H., Bjørgaas, M.R., Wisløff, U., et al. (2016) Exercise Training Normalizes Timing of Left Ventricular Untwistrate, But Not Peak Untwist Rate, in Individuals with Type 2 Diabetes and Diastolic Dysfunction: A Pilot Study. Journal of the American Society of Echocardiography, 29, 421-430. https://doi.org/10.1016/j.echo.2016.01.005

[19] Januzzi, J.L., Prescott, M.F., Butler, J., Felker, G.M., Maisel, A.S., McCague, K., Camacho, A., Piña, I.L., Rocha, R.A., Shah, A.M. and Williamson, K.M. (2019) Association of Change in N-Terminal Pro-B-Type Natriuretic Peptide Following Initiation of Sacubitril-Valsartan Treatment with Cardiac Structure and Function in Patients with Heart Failure with Reduced Ejection Fraction. JAMA, 322, 1085-1095.

https://doi.org/10.1001/jama.2019.12821

[20] D’Elia, E., Iacovoni, A., Vaduganathan, M., Lorini, F.L., Perlini, S. and Senni, M. (2017) Neprilysin Inhibition in Heart Failure: Mechanisms and Substrates beyond Modulating Natriuretic Peptides. European Journal of Heart Failure, 19, 710-717. https://doi.org/10.1002/ejhf.799

[21] Bayes-Genis, A., Barallat, J. and Richards, A.M. (2016) A Test in Context: Neprilysin: Function, Inhibition, and Biomarker. Journal of the American College of Cardiology, 68, 639-653. https://doi.org/10.1016/j.jacc.2016.04.060

[22] Wang, Y., Zhou, R., Lu, C., Chen, Q., Xu, T. and Li, D. (2019) Effects of the Angiotensin-Receptor Neprilysin Inhibitor on Cardiac Reverse Remodeling: Meta-Analysis. Journal of the American Heart Association, 8, e012272. https://doi.org/10.1161/JAHA.119.012272

[23] Januzzi, J.L., et al. (2019) Association of Change in N-Terminal Pro-B-Type Natriuretic Peptide Following Initiation of Sacubitril-Valsartan Treatment with Cardiac Structure and Function in Patients with Heart Failure with Reduced Ejection Fraction. JAMA, 322, 1085-1095.

[24] Romano, G., et al. (2019) The Effects of Sacubitril/Valsartan on Clinical, Bioumoral and Echocardiographic Parameters in Patients with Heart Failure with Reduced Ejection Fraction: The "Hemodynamic Reverse Remodeling".

https://doi.org/10.3390/jcm8122165

[25] Vitale, G., Romano, G., Di Franco, A., Caccamo, G., Nugara, C., Ajello, L., Storniolo, S., Sarullo, S., Agnese, V., Giallauria, F. and Novo, G. (2019) Early Effects of Sacubitril/Valsartan on Exercise Tolerance in Patients with Heart Failure with Reduced Ejection Fraction. Journal of Clinical Medicine, 8, 262. 
https://doi.org/10.3390/jcm8020262

[26] Buchalter, M.B., Rademakers, F.E., Weiss, J.L., Rogers, W.J., Weisfeldt, M.L. and Shapiro, E.P. (1994) Rotational Deformation of the Canine Left Ventricle Measured by Magnetic Resonance Tagging: Effects of Catecholamines, Ischaemia, and Pacing. Cardiovascular Research, 28, 629-635. https://doi.org/10.1093/cvr/28.5.629

[27] Yun, K.L., Niczyporuk, M.A., Daughters, G.T., Ingels, N.B., Stinson, E.B., Alderman, E.L., Hansen, D.E. and Miller, D.C. (1991) Alterations in Left Ventricular Diastolic Twist Mechanics during Acute Human Cardiac Allograft Rejection. Circulation, 83, 962-973. https://doi.org/10.1161/01.CIR.83.3.962

[28] Rademakers, F.E., Buchalter, M.B., Rogers, W.J., Zerhouni, E.A., Weisfeldt, M.L., Weiss, J.L. and Shapiro, E.P. (1992) Dissociation between Left Ventricular Untwisting and Filling. Accentuation by Catecholamines. Circulation, 85, 1572-1581. https://doi.org/10.1161/01.CIR.85.4.1572

[29] Dong, S., Hees, P., Siu, C., Weiss, J. and Shapiro, E. (2001) MRI Assessment of LV Relaxation by Untwisting Rate: A New Isovolumic Phase Measure of Tau. The American Journal of Physiology_Heart and Circulatory Physiology, 281, H2002-H2009. https://doi.org/10.1152/ajpheart.2001.281.5.H2002 